\title{
Seller-Buyer Conversation: Investigating the Discourse Strategies
}

\author{
Acheoah, John Emike (Ph.D) ${ }^{1 *}$, Beatrice Osaro Oreoluwa ${ }^{2}$, Aminu Garba Dandiga ${ }^{3}$ \\ ${ }^{1}$ Department of European Languages, Federal University, Birnin-Kebbi, Nigeria \\ ${ }^{2}$ Department of Linguistics, African and Asian Studies, University of Lagos, Lagos, Nigeria \\ ${ }^{3}$ Department of European Languages, Federal University, Birnin-Kebbi, Nigeria
}

DOI: $10.36348 /$ sijll.2019.v02i07.001

| Received: 30.08.2019 | Accepted: 06.09.2019 | Published: 20.09.2019

*Corresponding author: Acheoah, John Emike

\section{Abstract}

This paper is an overview of the discourse strategies involved in buyer-seller conversational exchanges. Discourse is truly human interaction, whether written or spoken. An analysis of discourse can simply be viewed as a conversational analysis. Contemporary use of the term discourse analysis covers several activities and disciplines which provide insights for the discourse analyst in the interpretation of language-use in a wide range of discourses or genres, including sellerbuyer discourse. This study hinges on both the Pragma-crafting Theory and Bach and Harnish's speech act theory for the analyses of data. The analyses reveal that in using language to communicate in different contexts and situations in buyerseller conversation, the interactants (the sellers and the buyers) demonstrate the various functions that language performs therein: to bargain, to persuade, to greet, to explain, to undertake, to confirm, to affirm, among others.

Keywords: seller-buyer conversation, discourse strategy, discourse, pragmatics, Pragma-crafting Theory, Bach and Harnish's Speech Act Theory.

Copyright @ 2019: This is an open-access article distributed under the terms of the Creative Commons Attribution license which permits unrestricted use, distribution, and reproduction in any medium for non-commercial use (NonCommercial, or CC-BY-NC) provided the original author and source are credited.

\section{INTRODUCTION}

This study is an investigation of communicative strategies used in seller-buyer interaction. The functions of language which include metalinguistic function, referential function, contextual function, among others, make it clear that language is an instrument of communication among human beings [1]. Discourse analysis is inseparable from what the term discourse means. The literature makes it clear that discourse is essentially language in use. This explains why the term is often defined in relation to social contexts or societal domains such as a market setting where the participants of discourse bargain via the instrumentality of language.

\section{The Literature}

In this section of the paper, two discrete fields of linguistic research are examined: discourse analysis and pragmatics.

\section{Discourse Analysis}

According to Stubbs, M [2], discourse is defined as "(1) concerned with language use beyond the boundaries of a sentence/utterance, (2) concerned with the interrelationships between language and society and (3) as concerned with the interactive or dialogic properties of everyday communication." The view that discourse analysis examines language use beyond linguistic norms (formal properties), is replete in the literature. Brown, G. and Yule, G [3] assert that "while some linguists may concentrate on determining the formal properties of a language, the discourse analyst is committed to an investigation of what that language is used for. While the formal approach has a long tradition, manifested in innumerable volumes of grammar, the functional approach is less well documented." In addition, the literature acknowledges the very close link between discourse and pragmatics. According to Brown, G. and Yule, G [3] "in discourse analysis as in pragmatics we are concerned with what people using language are doing and accounting for the linguistic features in the discourse as the means employed in what they are doing." Brown, G. and Yule, G. [3] also submit that "... the discourse analyst necessarily takes a pragmatic approach to the study of language in use. Such an approach brings into consideration a number of issues which do not generally receive much attention in the formal linguist's description of sentential syntax and semantics." Indeed, language use is believed to be a socially-situated phenomenon. Conversational structure which is crucial to the understanding of the term discourse is quite interesting. Brenders, D. O [4] notes that "coherent conversation involves both the coordinated production 
of illocutionary acts and the management of the potential perlocutionary effects of utterances." Bosco et al., [5] submit that "conversation is a two-fold activity in which the participants form utterances that are products of shared knowledge and such utterances produce felicitous results to the communication." Basically, discourse is conversational. Adegbija, E. F [6] defines conversation extensively:

"A conversation is a string of at least two turns. Each conversation typically involves speaker change. This occurs as the conversation progresses. Normally, one person speaks at a time but this is usually for a brief period. Transitions between one turn and the next with no gap and no overlap between them are common. Turn allocation techniques, which may vary from culture to culture, are used. Turn allocations are sometimes prearranged. A speech exchange often involves a single allocation of turns at a time though further turns may be negotiated as the discourse progresses. Turn taking concerns changes in the roles of speakers and addressees which occur successively, often with overlapping speech and a few periods of silence. Speaker change is often introduced by grammatical, phonological or semantic clues."

Relevance is crucial to discourse in terms of making human interaction coherent. Brown, $G$ and Yule, G [3] note that "the normal expectation in the construction and interpretation of discourse is, as Grice suggests, that relevance holds, that the speaker is still speaking of the same place and time, participants and topic, unless he marks a change and shows explicitly whether the changed context is, or is not, relevant to what he has been saying previously. Similarly, the normal expectation is that the discourse will be coherent." Topic (discourse subject) amplifies textual cohesion/coherence.

According to Stef, S [7] "the term discourse analysis is very ambiguous... Roughly speaking, it refers to attempts to study the organization of language above the sentence or above the clause, and therefore to study the larger linguistic units, such as conversational exchanges or written texts. It follows that discourse analysis is also concerned with language use in social contexts, and in particular with interaction or dialogue between speakers." Context phenomenon cannot be excluded from discourse.

\section{Pragmatics}

Pragmatics is a linguistic field of research immersed in non-formalist approach to language study. It emphasizes language users' supremacy over linguistic norms. Coined from the Greek word pragma (meaning deed or action), the term pragmatics has been subjected to different definitions. Barton, E [8] (1990) cites Morris who defines pragmatics as "the relation of signs to their users." Osisanwo, W. [1] cites Wales who defines pragmatics as "the study of language use which is concerned with the meaning of an utterance rather than a grammatical sentence or proposition." In addition, Crystal, D. and Varley, R [9] define pragmatics as "the study of the factors that govern our choice of language (sounds, construction, words) in social interaction, and the effects of our choice upon others." Mey, J [10] posits that pragmatics "studies the use of language in human communication as determined by the conditions of the society."

When sellers and buyers engage in a conversational exchange, inference-making operates immediately. Inference means making logical conclusions from all that a particular context provides to arrive at what a speaker means by uttering certain words. Decoding utterances involves the making of inferences that are either assumptions or uttered expressions. When utterances are uttered, the hearers have to reasonably establish the rationale for working out the meanings.

\section{Theoretical Frameworks}

The theoretical frameworks for the analysis of data are presented below. The analyses are mainly anchored by the Pragma-crafting Theory. However, the study hinges on Bach and Harnish's speech act taxonomy for the classification of discourse strategies (illocutionary acts) performed in the selected conversational exchanges.

\section{The Pragma-crafting Theory}

The Pragma-crafting Theory (cf. Acheoah, J. E [11] reveals that in using language and interpreting language-use, a wide range of Pragma-crafting Features (P-crafting Features) are involved. Pragma-crafting involves "illocrafting", "uptake" and "sequel". At different stages of a communicative event, there is a candidate for inference. At every such stage, the interactive and non-interactive participants explore $\mathrm{P}$ crafting Features (inference features): indexicals (INDXLs), Shared Macro-knowledge (SMK), Shared Contextual Knowledge (SCK), Shared Knowledge of Emergent Context (SKEC), Geoimplicatures (GIs), Linguistic Implicatures (LIs), Behavioural Implicatures (BIs), Contextual Presuppositions (CPs), Pragmadeviants (PDs), Object Referred (OR) and Operative Language (OL) - to ascertain messages and sequels." Notions in the theory include:

- P-crafting: This is a super-ordinate notion which has dual components: Event and Text; these two components unfold as discrete multiple categories in the explanation of how communication is interpreted from speakerhearer or writer-reader ends.

- Event: It concerns participants of discourse who are either interactive or non-interactive. The interactive participants perform any or all 
of these acts to the discourse: linguistic, extralinguistic and psychological acts. On the other hand, the Non-interactive Participants are those who are present in the setting, but do not perform any act in the discourse. Even when they perform linguistic, extra-linguistic or psychological acts, such acts are not connected to the on-going communication. Discourse in progress, so they are labeled as "Noninteractive Participants". Acheoah, J. E [11] exemplifies the notion thus: Billy, Gerald and Jane may begin a conversation from school and sustain it until they get to Hardy's shop, only to meet Hardy and his customer bargaining over the price of certain commodities. In this situation, all acts performed are only meaningful in terms of how they affect an on-going discourse. In another vein, the students in a classroom lecture are fragmented: some are discussing issues unrelated to the lecture; some are making linguistic, extra-linguistic and psychological contributions related to the lecture and others are just physically present in the setting. However, in certain discourse situations, an interactive participant may perform linguistic, extra-linguistic or psychological acts as an indirect communicative strategy targeted at a noninteractive participant towards achieving certain goal(s). Indeed, Non-interactive Participants affect communicative events. For example, the sociolinguistic particulars (age, status, ethnic background) of the NonInteractive Participants determine how and what Billy, Gerald and Jane say in Hardy's shop. Acheoah, J. E [12] uses the label " $\mathrm{H}_{2}$ " to refer to participants who are present in discourse, but are not speakers' interlocutors.

- Text: Components of Text are Setting, Theme and P-crafting Features. The trio constitutes the communicative features in Text. However, the dynamics of communication are captured by P-crafting Features which have discrete theoretical notions demonstrated by the Interactive Participants in three different frames: linguistic acts, extra-linguistic acts and psychological acts.

- Interactive participant: This is an interlocutory participant. He makes linguistic, extralinguistic and psychological contributions that do not only impinge on the interpretive process in discourse, but also determine or generate sequel. An Interactive Participant demonstrates pragmatic awareness in the encoding and decoding of utterances.

- Non-interactive Participant: A participant is categorized as non-interactive when he does not function in an on-going communicative event, although he is intentionally or accidentally present in the physical context.

- Setting: This is the physical context of the communicative event (Text) in both remote and immediate sense.

- Theme: This category is the message conveyed in/by Text. Text may convey one or more themes that can only be identified when communicative acts (acts performed by Interactive Participants) interact with communicative features (P-crafting Features).

- P-crafting Features: These elements are instrumental to understanding the interlocutory roles of the Interactive Participants. The elements include: Inference, Indexical Shared Macro-knowledge, Shared Contextual Knowledge, Shared Knowledge of Emergent Context, Geoimplicatures etc.

Inference has to do with making logical deductions from available linguistic and extra-linguistic data. Indexicals are grammatical categories that have the potential to establish the relationship between language and context. Shared Contextual Knowledge is the available pieces of information which only participants of the on-going discourse have for the communication to thrive. When discourse has an Emergent Context, perlocutionary effects may not occur (effects intended by speakers), despite the appropriateness of participants and circumstances. Any situation that suddenly emerges in an on-going discourse is emergent. An Emergent Context becomes Shared Knowledge of Emergent Context when it translates to common knowledge to the participants of discourse. It is vital in terms of its potential to determine illocutionary forces and relocate sequel. It is a candidate for inferences. The term Geoimplicature is coined from geographical and implicature to refer to practices that have geographical restriction in terms of people, and not just in terms of physical boundaries (cf. Acheoah, J. E [13]. Such practices are not universal, and they are both verbal and non-verbal. Linguistic implicatures are meanings implied through language while Behavioural implicatures are meanings implied through extra-linguistic and psychological acts. Contextual Presuppositions are products of Shared Contextual Knowledge; in a specific discourse, participants deduce meanings from verbal and nonverbal data limited to them. The meanings deduced are treated as Background Assumptions (BAs) which direct interlocutory roles. DCs (Decoders) imply that ENCs (Encoders) know that certain VEs (Verbal Elements) and NVEs (Non-verbal Elements) are deduced as OR (Object Referred) in OL (Operative Language).

- Linguistic Acts: There are five components in this category:

1. Speech acts (direct, indirect and pragmadeviant); 
Pragmadeviants are deviant forms of expressions which participants use as part of illocutionary strategy or creative indulgence.

Acheoah, J. E [13] coins the term "Pragmavediant" (PD) from "pragmatics" and "deviant". It is not a duplication of the notion of indirect speech act as it is any expression used as a literal but deviant communicative strategy. For example, in the conversational exchange below, Sam deviates from the conventional use of the verb "stole" since he owns the book:

Sam: I stole my book from the teacher's bag.

Mary: But it's yours.

There is always a pragmatic justification for pragmadeviating; Sam's book was no longer his, because his teacher who seized it did not promise to return it.

Object referred (OR) is the referent of an utterance. This referent is either in the remote world or immediate context of speech. One of the strengths of "meaning as object" (an approach to the study of meaning in semantics) is that words have or pick referents (objects) in the world.

Every natural communication is conveyed through a particular language, whether indigenous or alien to the participants. This is what Acheoah, J. E [11] refers to as Operative Language.

2. Supra-segmental Features (stress, intonation, rhythm, pitch);

Stress is the degree of emphasis with which a syllable is uttered. Intonation is the rising and falling of the voice during speech production. The noticeable pattern of sound produced as a result of stressed and unstressed syllables produces rhythm. Therefore, speakers' intentional violation of the stress patterns of words or stretches can convey varied messages in discourse. During a class lesson, the pupils who have become too tied to continue the lesson may choose repeated pitch rhythm (and this can generate the perlocutionary effect of annoying the teacher) to respond to the teacher when they are asked: "Pupils, do you understand?" Indeed, stress, intonation and rhythm are mostly inseparable. These prosodic features convey messages in communicative events.

\section{Phones (Ssss, Shhh, Mmmm, Ehmnn);}

The term 'phones' refers to speech features between the phoneme and the word. They are common components in both written and spoken discourse. Small as they are, they express emotions of various kinds besides having speech acts illocutionary potential in context.

4. Exclamations (Wao!, Oh!, Ah!, Abah!, other categories);

Psychological acts are sometimes performed through exclamations. A speaker may utter "Oh!" in a particular context of situation to perform the act of approving whereas the same speaker may utter "Abah!" to agitate in the same context of situation.

\section{Music (lyrical).}

Participants can sing without using words (lyrics). However, it is when words are used that it can be said that a linguistic act has been performed. Lyrics convey diverse messages in discourse. Sometimes, the context in which a participant of discourse sings, and how it is sung, determines the implicature.

- Extra-linguistic Acts: Extra-linguistic acts in the Pragma-crafting Theory include:

1. Sociolinguistic Variables: These include: age, cultural background, social status/class, gender and relationships).

2. Music (non-lyrical): Non-lyrical music operates as non-verbal communication. It can be rhythmic, but its importance in the Pragmacrafting Theory is its communicative value in discourse. Sounds produced in rhythmic pattern in certain contexts may negate world knowledge, and so become an implicature or an illocutionary strategy.

3. Drumming: Where a group of students are writing an examination, drumming generates a Behavioural implicature (BI), which is produced when extra-linguistic acts negate the context of discourse.

4. Semiotic particulars (weather, time, contextual object (CO), colour, clothing, posture, perfume, location/position, size, body mark and silence);

5. Laughter: Laughter is capable of conveying expected emotions of solidarity, peace, approval, admiration, etc.

6. Body Movement: Not all body movements are gestures. Like gestures, body movement can reveal psychological states of participants, besides being able to achieve communicative goals.

7. (xi) Psychological Acts: These are the different emotions expressed through linguistic and extra-linguistic acts.

Figure-1 below shows theoretical concepts in the Pragma-crafting Theory (cf. Acheoah, J. E [11]: 


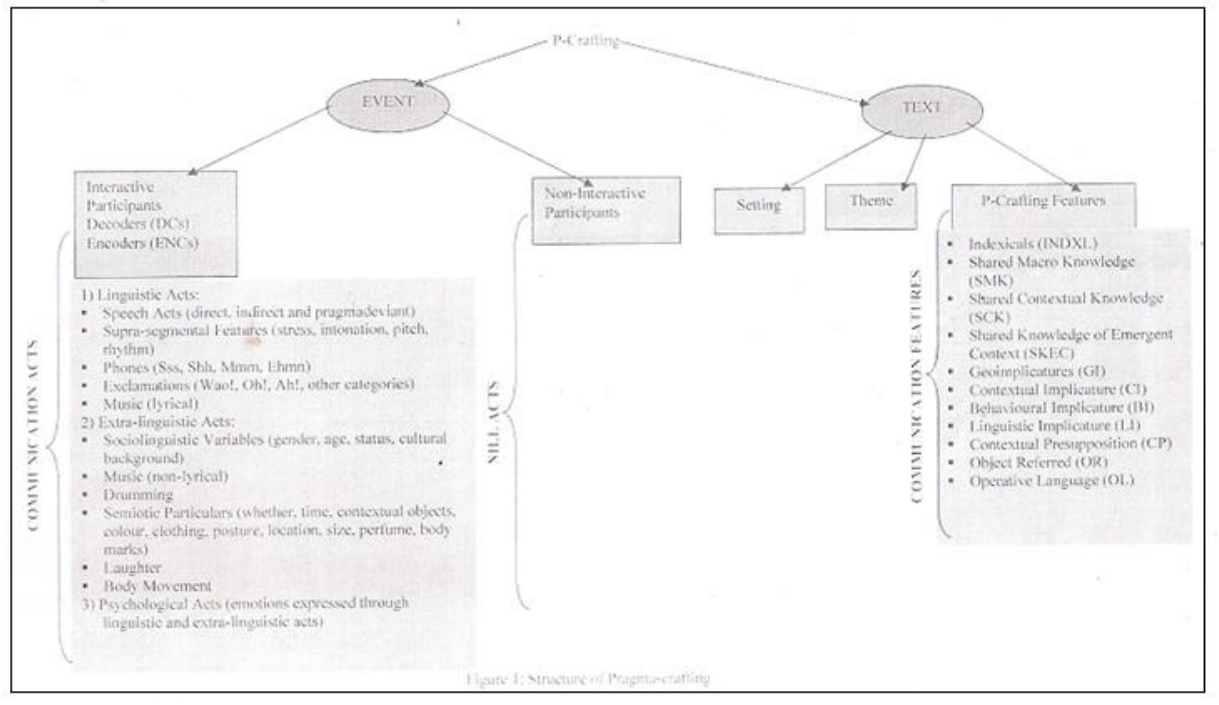

Fig-1: Theoretical Concepts in the Pragma-crafting Theory

\section{Bach and Harnish's Speech Act Theory}

Although Austin, J. L [14] is the pioneer of speech act theory, scholars after him have improved the study of speech act, as evident in the literature. The speech act theory of Bach, K. and Harnish, R [15] is based on inference-making and speakers' intention(s). They contend that for speakers to perform illocutionary acts, it is intended that listeners have the understanding of the acts. They view conversation as an inferential activity. Speech act categories in the speech act taxonomy of Bach, K. and Harnish, R [15] include: Assertives, Informatives, Confirmatives, Concessives, Acriptives, Retractives, Assentives, Dissentives, Disputatives, Responsives, Suggestives, Suppositives, Descripives, Directives and Advisories.

According to Bach, K. and Harnish, R [15], Assertives are characterized by S's expression of belief that the hearer $(\mathrm{H})$ also believes that P. Examples of verbs denoting Assertives speech acts are affirm, allege, assert, aver, avow, declare, and deny.

Informatives are speech acts in which $\mathrm{S}$ expresses the belief that $\mathrm{P}$ and also "the intention that $\mathrm{H}$ form the belief that P." Examples are advice, announce, appraise, disclose, inform, insist, notify, point out, report, reveal, tell, and testify.

In Descriptive speech acts, $\mathrm{S}$ declares that a particular quality is possesed by a person, place or thing. That is, $\mathrm{S}$ expresses "the belief that $\mathrm{O}$ is F" and "the intention that $\mathrm{H}$ believes that $\mathrm{O}$ is F". Examples are appraise, asses, call, categorize, characterize, classify, date, describe, diagnose, evaluate, etc.

In directives, the speaker's attitude toward a future action by the hearer $(\mathrm{H})$ and the speaker's intention or desire that $\mathrm{H}$ consider his utterance as reason to act (A) is expressed. Six subcategories of illocutionary acts are listed under this category: Requestives, Questions, Requirements, Prohibitives,
Permissives, Advisories. In Bach and Harnish's framework, Questions are "special cases of requests in that what is requested is that the hearer provide the speaker with certain information". A speech act is considered a question if $\mathrm{S}$ expresses "the desire that $\mathrm{H}$ tell $\mathrm{S}$ whether or not $\mathrm{P}$ " and "intention that $\mathrm{H}$ tell $\mathrm{S}$ whether or not P because of S's desire". Examples of verb denoting Questions are ask, interrogate, query, questions, quiz, etc. Advisories, they explain, is a speech act in which the speaker expresses the belief that "there is (sufficient) reason for $\mathrm{H}$ to $\mathrm{A}$, ," and "the intention that $\mathrm{H}$ takes S's belief as (sufficient) reason for him to A". Examples are advice, caution, counsel, propose, recommend, suggest, urge, warn, etc.

The third major category of speech acts established by Bach, K. and Harnish, R [15] is Commissives. They are acts involving the undertaking of an obligation or proposal to undertake an obligation. Two main types of this category are distinguished: Promises and Offers. S promises $\mathrm{H}$ to A if $\mathrm{S}$ expresses "the belief that his utterance obligates him to A", "the intention to A", and "the intention that $\mathrm{H}$ believes that S's utterance obligates S to A and that S intends to A". Contracting, Guaranteeing, etc. are examples of this category. Promise include swear, vow, surrender and guarantee. A speech act is said to be an Offer if $S$ expresses "the belief that S's utterance obligates him to A on condition that $\mathrm{H}$ indicates he wants S to A" and "the intention that $\mathrm{H}$ believes that $\mathrm{S}$ 's utterance obligates $\mathrm{S}$ to $\mathrm{A}$ and that $\mathrm{S}$ intends to $\mathrm{A}$ on condition that $\mathrm{H}$ indicates he wants $\mathrm{S}$ to $\mathrm{A}$ ". Examples of verbs denoting speech acts in this category are volunteer, offer, and propose. Acknowledgements, the final category of Bach and Harnish's communicative illocutionary acts, are very common in our day to day interaction. They express perfunctorily, if not genuinely, certain feelings toward the hearer". Examples of verbs denoting members of this category include greet, thank, condole, apologize, congratulate, etc. 


\section{METHODS}

In this section, the methods of selecting the data as well as the methods of analyzing them, are presented.

\section{Method of Selection of Data}

This study analyzes selected texts from recorded conversations in two different Nigerian markets. Four corpora (Corpus 1- Corpus 4) are selected using three basic parameters: length of the conversational turns, quality of pragmatic forces and variation of discourse strategies. Given the fact that the conversational exchanges (adjacency pairs) in each corpus are long, four corpora will suffice for the investigation of discourse strategies used by the participants.

\section{Method of Analysis}

Due to the external properties of texts, an integrative and sociological approach to textual analysis is not negotiable. Every text (discourse) has a structure (organization) which the discourse analyst analyzes to reveal the actions (speech acts) that language performs therein.

Exploring the Pragma-crafting Theory, an integrative analysis is done in this study, with a view to revealing the discourse strategies used by the participants and the communicative functions (illocutionary forces) of such strategies. Meaning changes in relation to people, language and extralinguistic institutions (states-of-affairs). The central goal of the various approaches to textual analysis is therefore to apply an integrative model for the analysis of the nature of language. In analyzing the data of this study, references are made to the literature as they apply to each corpus. In-text references are infused into the analyses depending on how such references corroborate the P-crafting Features evident in the conversational exchanges (implicatures, speech acts, shared knowledge, inferences, etc.).

\section{Presentation and Analysis of Data Corpus 1:}

Buyer: How much do you sell tomatoes?

Seller: They are not the same price. Which ones do you want?

Buyer: What about these? Yes, these.

Seller: Two hundred naira. My tomatoes are different. I know where I buy my tomatoes.

Buyer: I want to pay Three hundred naira for two. These and those ones. You have to sell them like that. I am your regular customer.

Buyer: Madam. I don come again. Na where I go get better garri?

Seller: Abah! My garri is good?

Buyer: Are you sure?

Seller: I no fit lie to you. It is good for drinking and for eba.

Buyer: Okay. I need three mudu.
Seller: Na nine hundred naira.

Buyer: Madam, I get my own customer. But she no dey market today. Even all other shops do not sell it as expensive as you sell. I pray that Mama Chuks will not eventually catch me here. Give me reduction. I will pay seven hundred naira for them.

Seller: I did not get it to buy at that rate. I did not.

\section{Analysis}

The seller ascribes good quality (Ascriptive speech act) to the product - saying that it is different from others. The buyer asks direct questions, not just to know the price of the tomatoes, but also to bargain and get favourable price. As evident in the text, direct questions and answers also function in terms of seeking information and getting the right answers. The expression "My tomatoes are different" (declarative clause) is an intentional exaggeration; after all, it is not certain that the seller had gone to all the other shops in that market to ascertain that her own tomatoes are different from those of other sellers. On hearing the remark "My tomatoes are different. I know where I buy my tomatoes", a buyer becomes more willing to buy the tomatoes instead of going through the difficulty of pricing tomatoes in all the other shops in that market. The seller's utterance was constructed with the understanding that the buyer will decode it as intended (Linguistic Implicature and Contextual Presupposition). The seller uses extra-textual reference as a discourse strategy; after making reference to Mama Chuks, the buyer expects the seller to comply immediately - to accept the price she wants to offer having abandoned Mama Chuks whom she had been patronizing. Within the framework of the Pragma-crafting Theory, "Mama Chuks" is Object Referred, an instrument of textual communication. The use of indirect accusation ("Even all other shops do not sell it as expensive as you sell") can indeed, culminate into price-reduction. There is also exaggeration in the text. The seller uses polite refusal strategy; instead of saying "No" to the request, she says "I did not get it to buy at that rate. I did not" (Behavioural Implicature combined with repetition). The repetition of the negative clause is for emphasis to make the buyer believe the seller's claim. In Corpus 1 , it is obvious that the participants use language to achieve specific illocutionary goals. This practice captures the word-to-world direction of fit postulated by Searle, J [16]. The postulation holds the view that human utterances make things happen in the real world (universe of discourse).

\section{Corpus 2:}

Seller: Good morning, mama twins. Buy these ones for oga. Come and buy, aunty.

Buyer: Good morning.

Seller: I will give you jara.

Buyer: Make I taste am?

Seller: Why not, my customer. 


\section{Analysis}

The seller's greeting is a Requestive speech act (persuasive greeting). Even if a person is not known by a seller, but walks close to the seller's shop, the seller who is willing to sell, is expected to draw the attention of the passer-by through a friendly disposition as if there were a pre-existing relationship between them. This is what we experience when we go to markets to buy things (Macro-shared Knowledge). The seller introduces third-party ("oga") to persuade the buyer (call to action). Introducing third-party takes the discourse to another dimension. If the buyer is not in need of the product, it is possible that "oga" (Object Referred) is in need of it. Some wives can be very emotional when they hear that there is a product that their husbands would need. The kind of request made by this seller tests wives' love for their husbands. Therefore, it can be concluded by extension, that sellers target the psychological context that underpins a communicative event, and explore such context for effective, result-producing communication. The expression "aunty" is an Ascriptive speech act. Even if the buyer is not old enough to be regards so, a seller can utter the expression to make the buyer feel esteemed, and this can produce a positive result - inducing a person to purchase a product (intended perlocutionary act). "I will give you jara" is a Commissive speech act the seller is undertaking to give an unsolicited favour, just to induce the buyer to buy the product. The speech acts performed in this corpus (questioning, answering, requesting, persuading and explaining) are informed by the discourse subject which is to buy or sell a product. According to van Dijk, T [17] cited in Brown, G. and Yule, G [3], "discourse topics seem to reduce, organize and characterize semantic information of sequences wholes." In addition, Brown, G. Yule, G [3] note that "within the presupposition pool for any discourse, there is a set of discourse subjects and each discourse is, in a sense, about its discourse subjects. Because it is part of the shared assumptions of the discourse participants that these discourse subjects exist, they do not need to have their existence asserted in the discourse."

\section{Corpus 3:}

Seller: Buy fresh ukpoka.

Buyer: Are they today's ukpoka?

Seller: My fish? I don't sell yesterday's market. How are my children?

Buyer: They are doing fine. Thank you. How is your family?

Seller: We thank God. We all are fine. God will bless us. These are the ones you want? When you reach home, first wash am with salt then...

Buyer: Exactly.

Buyer: I need this as well.

Seller. Okay. Nine thousand naira.

Buyer: Let me pay seven thousand five hundred naira.
Seller: No.

Buyer: How much is the last price?

Seller: Try buy it. You will like to come back next time. I give you one year guarantee. Touch am see. This one na confirm. Na carrygo.

\section{Analysis}

The question "How are my children?" establishes affectionate relationship. In a similar vein, the prayer "God will bless us" is used by the hearer to align with the feeling of new seller-buyer relationship. In this corpus, Explanation is a speech act, that is, the seller explains how the product is used. The perlocutionary effect of this speech act is motivation (encouragement). Sellers' instructions, even when unsolicited, help buyers to use whatever they purchase. Fowler, R [18] posits that "linguistic structure is not arbitrary. It is determined and motivated by the functions language performs." Corroborating this submission, Adegbija, J. E [6] opines that "language use is not incidental. It is of credit." Speech acts in this corpus include: Requestive (requesting reduction in price); Question (the interactants ask questions to get answers); Responsive/Answer (the interactants respond to questions); Declarative (the participants make constatives on different Object Referred e.g. "This one na confirm" in Corpus 3) [1]. In the conversations, the Operative Language (OL) is bipartite (English and Nigerian Pidgin). The geographical locale of the text (Nigeria) has informed the two-fold linguistic medium of communication. The status (age or level of education) of the participants is likely to have impinged on the code-switching evident in this corpus. In the Pragma-crafting Theory, age is a component of sociolinguistic variables.

\section{Corpus 4:}

Seller: Welcome. Na new market be dis. I just dey open bail. You will not meet it if you come tomorrow.

Buyer: Do you have the other type I usually buy from you? No. This is what people are using now. I also sell tubers of yam.

Buyer: Are they good for pounded yam?

Seller: These are Abuja tubers of yam. Return am if I lie.

The entire stretch: "Na new market be dis. I just dey open bail. You will not meet it if you come tomorrow" is persuasive information. As soon as it is uttered, it "invades" any decoder's sense of reasoning and he/she will then be ready to buy the product. Ascriptive abounds in this corpus ("... Abuja tubers of yam"). The question-answer conversational turns in this corpus perform several discourse functions: dislodging a request, call to action, making comparison, making an undertaking (Commissive), persuading, etc.

It should be noted that because of the 
underlying purpose of seller-buyer discourse, Corpus 1 - Corpus 4 contain Persuasion (speech act).

The actions or speech acts that language is used to perform is particularly evident when one considers the fact that texts have external relations - revealing social systems, ideologies, beliefs and several pragmatic forces. Texts have histories so, intertextuality is a crucial component of discourse.

\section{RESULTS AND DISCUSSION}

The analyses reveal that discourse strategies in the conversations include: Direct Question and Answer, Declarative, Explanation (Instruction), Commissive, Confirmative, Affirmation, Exaggeration, Extra-text Reference (Third-party), Indirect Accusation, Requestive, Repetition, Nigerian Pidgin (CodeSwitching), Ascriptive, Persuasion, Prayer, Comparison and Call to action.
The discourse strategy with the highest percentage is direct Question (21.4\%). This is followed by Nigerian Pidgin (14.3\%). Those with the least percentage are: Call to action, Confirmative, Affirmative, Exaggeration, Indirect Accusation, Repetition and Prayer (1.8\% each). As part of the discourse strategies, the frequency of Answer is less than that of Question because in some of the instances of the conversations, a speaker asks more than one question. There are instances of non-compliance to the principles of turn-taking. For more insights on the Cooperative Principle of conversation, see Grice 1976 cited in Adegbija, E. F [6]. An example of noncompliance is in Corpus 3 where the encoder of "My fish?" has used a question to answer a question. In this study, series of sentences that form an answer to a question are taken as a single answer in the quantification of the discourse strategies. In all, sellerbuyer conversations analyzed in the entire four corpora reveal the statistics in Figure-2 below:

\begin{tabular}{|c|c|c|c|}
\hline Discourse Strategy & Frequency & Percentage & Illocutionary Force (Communicative \\
\hline Call to action & 1 & $1.8 \%$ & - to persuade \\
\hline Declarative & 2 & $3.6 \%$ & $\begin{array}{l}\text { - to inform; } \\
\text { - to persuade. }\end{array}$ \\
\hline Explanation (Instruction) & 2 & $3.6 \%$ & $\begin{array}{l}\text { - to inform; } \\
\text { - to persuade. }\end{array}$ \\
\hline Commissive & 2 & $3.6 \%$ & - to persuade \\
\hline Confirmative & 1 & $1.8 \%$ & $\begin{array}{l}\text { - to inform; } \\
\text { - to persuade. }\end{array}$ \\
\hline Affirmation & 1 & $1.8 \%$ & $\begin{array}{l}\text { - to inform; } \\
\text { - to persuade. }\end{array}$ \\
\hline Exaggeration & 1 & $1.8 \%$ & $\begin{array}{l}\text { - to persuade; } \\
\text { - to inform. }\end{array}$ \\
\hline Extra-text reference (Third Party) & 2 & $3.6 \%$ & - to persuade \\
\hline Indirect accusation & 1 & $1.8 \%$ & $\begin{array}{l}\text { - to condemn; } \\
\text { - to agitate; } \\
\text { - to persuade. }\end{array}$ \\
\hline Requestive & 4 & $7.1 \%$ & $\begin{array}{l}\text { - to bargain; } \\
\text { - to request; } \\
\text { - to ask. }\end{array}$ \\
\hline Repetition & 1 & $1.8 \%$ & - to persuade \\
\hline Nigerian Pidgin (Code-switching) & 8 & $14.3 \%$ & $\begin{array}{l}\text { - to persuade; } \\
\text { - to explain; } \\
\text { - to ascribe. }\end{array}$ \\
\hline Ascriptive & 3 & $5.4 \%$ & $\begin{array}{l}\text { - to ascribe; } \\
\text { - to persuade. }\end{array}$ \\
\hline Persuasion & 4 & $7.1 \%$ & - to convince \\
\hline Prayer & 1 & $1.8 \%$ & $\begin{array}{l}\text { - to persuade; } \\
\text { - to request. }\end{array}$ \\
\hline Comparison & 2 & $3.6 \%$ & $\begin{array}{l}\text { - to ascribe; } \\
\text { - to inform; } \\
\text { - to declare; } \\
\text { - to persuade. }\end{array}$ \\
\hline Direct question & 12 & $21.4 \%$ & $\begin{array}{l}\text { - to ask; } \\
\text { - to request. }\end{array}$ \\
\hline Direct answer & 8 & $14.3 \%$ & $\begin{array}{l}\text { - to respond; } \\
\text { - to assent; } \\
\text { - to dissent; } \\
\text { - to persuade. }\end{array}$ \\
\hline
\end{tabular}

Fig-2: Distribution of Discourse Strategies 
As shown in this study, the use of language in market conversations is more immersed in the relationship between the encoder and the utterance on the particular occasion of use, than with the relationship which the sentential elements have. That is, in using Pragma-crafting Features (reference, implicatures, shared knowledge, inference or presupposition), the discourse analyst describes what sellers and buyers are doing, and not the relationship which holds between the linguistic units in isolation or as stretches.

Market conversations are a component of social system. Discourse examines social structure of society: markets, work places, schools, churches, hospitals, etc. Social structure is dynamic and a field of linguistic enquiry that constructs/reconstructs social system or structure is discourse analysis. Extralinguistic features of social structure are part of the domain of discourse analysis. In any seller-buyer interaction, references are made to extra-linguistic forces (states-of-affairs) as they relate to the ongoing conversation. The concept of reference explains the extra-linguistic nature of discourse; discourse is about social systems/institutions. According to Adegbija, E. F. [6] "reference is concerned with the relations between language and extra- linguistic reality. That is, with what words stand for in the outside world of the universe of discourse." In a similar vein, Lyons, J. [19] posits that "reference is the relationship which holds between an expression and what that expression stands for in the outside world." There are submissions from other scholars on the definition of reference. For example, Strawson, P. F [20] submits that "it is the speaker who refers (by using some appropriate expression): he invests the expression with reference by the act of referring." Lyons, J [19] notes that "'referring' is not something an expression does; it is something that someone can use an expression to do."

Buying and selling of goods involve certain conventional practices. The process is therefore ideological.

Due to the references that are made to statesof-affairs in seller-buyer conversations, intertextuality operates in such discourse. Intertextuality is crucial to the understanding of discourse. As far as micro notions such as text, talk, meaning and understanding are concerned, intertextuality is pivotal to the understanding of discourse. Depicting intertextuality, Brown, G. and Yule, G. [3] posit that "there is, for most conversational fragments, a set of discourse-internal elements which are derived from the conversation prior to the particular fragment being studied."

The participants who are engaged in buying and selling of products infer meanings from utterances via social cognition. Social cognition has immense role to play in the understanding of micro notions of discourse. See Chilton, P [21] for insights on the concept of social cognition. This study demonstrates the significance of Corpus Linguistics in textual interpretation. Grabinska, T. and Zielinska, D [22] submit that "Corpus Linguistics (CL) is an especially promising framework of language description avoiding many of the pitfalls of the classical model."

A proper or adequate description of language examines the key components of conversation which Adegbija, E. F [6] examines:

- What is the conversation or discourse about? Put differently, what is the topic?

- What comments are being made about this topic?

- Who are the speakers and addressees and what are their roles and relationship?

- How is turn taking effected? What are the turn allocation techniques?

- How has the topic been linked from one speaker to another? Or how has coherence in discourse been achieved?

- How is reference made to different objects, persons, things, places? Is this done backwards, within the text, or outside the text?

- How is meaning decoded from the discourse? (What contributions do the contexts of discourse make to the encoding and decoding of the meaning?).

- What specific and overall functions do the different utterances in the discourse perform?

- How is the discourse terminated by participants?

- What specific function does the discourse perform in the particular social-cultural context?

Sellers and buyers communicate intentions skillfully so that their illocutionary goals can be achieved. Giddens, A [23] opines that “... there are a variety of ways in which individuals can express intentions, provide approval or disapproval, or otherwise make their views known, without directly committing themselves to turn-taking within the conversation. A key aspect of all talk in situations of interaction is that both speakers and listeners depend upon a saturated physical and social context for making sense of what is said [2]."

\section{CONCLUSION}

Meaning-interpretation is crucial in sellerbuyer conversations. The use of various discourse strategies in the conversations is essentially the demonstration of how meaning interact with participants' illocutionary goals. Savas, L. T [24] asserts that "the study of illocutionary act should be 
acknowledged as an indispensable component of the study of meaning." If one knows the illocutionary act performed in an utterance, one will definitely understand the speaker's communicative intention. The intentional nature of illocutionary acts is captured by David Harrah, cited in Savas, L. T [24] who notes that "most speech acts seem to be focused and directed. They are intended as coming from the agent and going to the receivers or audience..." This study reveals that fascinating dimensions of language use are conveyed by sellers and buyers in the process of selling or buying a commodity.

\section{Notes}

1. To understand performatives and constatives, see Austin, J. L [14].

2. Heritage, $\mathbf{J}$ [25] notes that " $\ldots$ it is fundamentally through interaction that context is built, invoked and managed... it is through interaction that institutional imperatives originating from outside the interaction are evidenced and are made real... for the participants."

3. The process presupposes skillful articulation of illocutionary acts in varied situations.

\section{REFERENCES}

1. Osisanwo, W. (2003). Introduction to discourse analysis and pragmatics. Lagos: Fetap Publishers.

2. Stubbs, M. (1983). Discourse analysis: The sociolinguistic analysis of natural language. Oxford: Basil Blackwell.

3. Brown, G., \& Yule, G. (1983). Discourse analysis. Cambridge: Cambridge University Press.

4. Brenders, D. O. (1982). Fallacies in the coordinated management of meaning: A philosophy of language critique of the heirachical organaization of coherent conversation and related theory. Quarterly Journal of Speech, 73, 329-348.

5. Bosco, F., Monica, B., \& Bruno, B. (2006). The fundamental context categories in understanding communicative intentions. Journal of Pragmatics 36, 467-48.

6. Adegbija, E. F. (Ed.) (1999). The English language and literature in English: An introductory handbook. Ilorin: University of Ilorin.

7. Stef, S. (1998-2003). What is meant by discourse analysis? Gent: Department of English, University of Gent.

8. Barton, E. (1990). Non-sentential constituents: A theory of pragmatics and grammatical structure. New York: John Benjamins Inc.

9. Crystal, D., \& Valey, R. (1993). Introduction to languages. London: Whurr Publishers.
10. Mey, J. (2001). An introduction to pragmatics. Oxford: Blackwell Publishing.

11. Acheoah, J. E. (2015). The pragma-crafting theory: A proposed theoretical framework for pragmatic analysis. American Research Journal of English and Literature, 1(2), 21-32.

12. Acheoah, J. E. (2014). The illocutionary frames principle (IFP) and the Austinian postulations: A clause-structure investigative discourse. Global Journal of Human and Social Sciences, 13(13), 21-29.

13. Acheoah, J. E. (2011). A pragmatic analysis of Ayi Kwei Armah's the beautyful ones are not yet born and Ola Rotimi's Hopes of the living dead. Ph.D. dissertation. Zaria: Ahmadu Bello University.

14. Austin, J. L. (1962). How to do things with words. Cambridge: Harvard University Press.

15. Bach, K., \& Harnish, R. (1979). Linguistic communication and speech acts. Cambridge: Massachusetts. The MIT Press.

16. Searle, J. (1969). Speech acts: An essay in the philosophy of language. New York: Cambridge University Press.

17. van Dijk, T. A. (1977). Text and context. London: Longman.

18. Fowler, R. (1981). Literature as social discourse: The practice of linguistic criticism. Bloomington: Indiana UP.

19. Lyons, J. (1977). Semantics 1. Cambridge: Cambridge University Press.

20. Strawson, P. F. (1952). Introduction to logical theory. London: Methuen.

21. Chilton, P. (2005). Missing links in mainstream CDA: Modules, blends and the critical instinct. In Wodak, R., \& Chilton, P. (Eds.) A new agenda in critical discourse analysis. Amsterdam: John Benjamins.

22. Grabinska, T., \& Zielinska, D. (2018). Linguistics from the perspective of the theory of models in empirical sciences: From formal to corpus linguistics. Technical Writing and Communication, 40(4), 379- 402.

23. Giddens, A., Goffman as a systematic social theorist. In Drew, P., \& Wootton, A. (Eds.) Erving Goffman: Exploring the interaction order. Cambridge: Polity Press.

24. Savas, L. T. (Ed.) (1994). Foundations of speech act theory. London: Routledge.

25. Heritage, J. (1998). Conversational analysis and institutional talk. In Silverman, D. (Ed.), Qualitative research: Theory, method and practice. London: Sage. 